\title{
Management of Mathematics Anxiety through Behaviour Technology, Super Brain Yoga and Varmalogy in
}

\author{
Ninth Standard Students
}

\author{
Pankaj Singh ${ }^{1 *}$
}

\section{ABSTRACT}

This research is carried out on 35 students of IX standard, Kendriya Vidalaya. Students were selected for the therapy on the basis of their SUD score. After taking Math autobiography it was revealed that anxiety in Mathematics for the students was developed due to various causes and the students were not Dyslexic. Student's average score in the recent Mathematics exam was noted. Mathematics Anxiety was assessed by using Suri, Monroe and Koc's (2012) short Mathematics Anxiety Rating Scale and their hemispheric dominance of the brain was measured by using Taggart and Torrance's Human Information Processing Survey (1984). Students were treated with Behaviour Modification techniques, Adappa Kalam and Super Brain Yoga for four weeks. For the study Interventions used are: (i) Reduction of Rate of Breathing (Ganesan, 2012). (ii) Laughter Technique (Ganesan, 2008). (iii) Develpoment of Alternate Emotional Responses to the Threatening Stimulus (Ganesan, 2008). (iv) Adappa Kalam (Shunmugom, 2014) (v) Super Brain Yoga (Sui, 2005). The Anxiety level and performance in Mathematics exam was reassessed after four weeks. Results showed that group's Mathematics Anxiety and Mathematics SUDs were significantly reduced from 65.14 to 52.49 and 60.63 to 48.29 respectively. Eventually, it significantly improved the group's average performance in Mathematics exam from 51.43 to 58.60. This shows that Behaviour Modification techniques, Adappa Kalam and Super Brain Yoga are efficient in treating Mathematics Anxiety.

Keywords: Mathematics Anxiety, Behaviour Modification, Super Brain Yoga, Adappa Kalam.

Behaviour Modification is the traditional term for the use of empirically demonstrated behaviour change techniques to increase or decrease the frequency of behaviour. For example increasing it by Positive or Negative Reinforcement and decreasing it by Punishment or Extinction. The foundation for Behaviour Modification was laid late in the $19^{\text {th }}$ century in the

\footnotetext{
${ }^{1}$ Research Scholar, Psychology, R \& D Centre, Bharathiar University, Coimbatore, Tamil Nadu, India *Responding Author (C) 2016 I P Singh; licensee IJIP. This is an Open Access Research distributed under the terms of the Creative Commons Attribution License (http://creativecommons.org/licenses/by/2.0), which permits unrestricted use, distribution, and reproduction in any Medium, provided the original work is properly cited.
} 


\section{Management of Mathematics Anxiety through Behaviour Technology, Super Brain Yoga and Varmalogy in Ninth Standard Students}

experimental laboratory of Russian physiologist Ivan P Pavlov which led to conceptualization of classical conditioning. His Noble prize winning research work on dog's digestive system led to the inception of classical conditioning. John B Watson an American psychologist, who coined the term behaviorism in his influential paper in 1916, emphasized that habits are learned due to classical conditioning and also demonstrated it in a classical experiment (Watson \& Rayner, 1920). Behaviour Modification is based on the learning theories and its basic principle is that when we consistently respond to a stimulus in a particular manner neural network forms and it becomes habit. Habits can be learned and unlearned through Behaviour Modification. Further, in 1950s Joseph Wolpe research work based on Pavlovian conditioning and Sherrington (1947) observation led to inception of Reciprocal Inhibition. He extended the principal of reciprocal inhibition to state that if a response that is incompatible with the learned fear or anxiety can be made to occur to a stimulus that had been conditioned to produce that fear, then that stimulus will cease to elicit the fear reaction. Based on Sherrington (1947) observation, that if one group of muscles is stimulated, an antagonistic muscle group will be inhibited, and vice versa, Joseph Wolpe propounded treatment for Anxiety and irrational fears. Anxiety is an unadaptive habit which is formed due to wrong learning and can be treated by relearning the behaviour to form adaptive habits. Similarly Mathematics-Anxiety is treated with Behaviour Modification by relearning and creating alternate responses to the threatening stimulus. Alternate responses are created on the principle of Reciprocal Inhibition where an incompatible response is produced to counter the negative stimulus. Mathematics which has become a threatening stimulus due to various reasons can be de-conditioned by practicing techniques based on reciprocal inhibition. It is also important to remember that it is the behavior which is troublesome, not the student. It is important to make this distinction even though in some cases a student may seem to continually try to test the patience. Separating the student from his or her behavior will help prevent and dissipate negative feeling that the therapist may have about a student and help to execute the intervention program effectively.

Varmalogy is a common nomenclature, which includes Defence Varmalogy, Spiritual Varmalogy, Yogic Varmalogy, Astronomical Varmalogy, Dietic Varmalogy, Medical Varmalogy and so on. All the branches of the Varmam art are necessary for the well-being of man. But Medical Varmalogy is the basis of all the other branches of Varmam art. Medical Varmalogy is used for the prevention of diseases and their management. The word Varmam belongs to the seventeenth century, which means energy. Varmam is the manifestation of the subtle energy of the five elements (Pancha Boota). Those places where this energy resides and activates both body and life are Varmam points. These points are located in nerves, muscles and bones. These Varmam points are divided into 12 Padu Varmam and 96 Thodu Varmam (Shunmugom \& Renuka, 2012). Padu Varmam are primary Varmams and are directly related to brain, whereas Thodu Varmams can be considered to be secondary points, which when touched gets connected to other Varmam points. When the energy flowing in these Varmam points gets hindered, related diseases occurs. Adappa Kalam is one of the Padu Varmam, which is located 


\section{Management of Mathematics Anxiety through Behaviour Technology, Super Brain Yoga and Varmalogy in Ninth Standard Students}

13 finger breadths lateral to the Ner Varmam (Solar Plexus) or xiphoid process in medical terminology in the flank of both the sides of the chest. It strengthens the blood vessels that reach the lungs (Varma Kaandam, Verse 810). So, correct stimulation of Adappa Kalam induces deep breathing, leading to activation of parasympathetic nervous system, which in turn alleviates the effect of sympathetic nervous system and thus is effective in the management of fear and phobias (Shunmugom, 2014).

Whereas, Super Brain Yoga is a technique which enhances Alpha waves in the brain and Synchronization of left and right brain hemispheres (Sui, 2005). Increase in Alpha waves in the brain indicates that the body has become relaxed and thus Super Brain Yoga is an effective tool to manage anxieties. Super Brain Yoga also synchronizes left and right brain hemispheres and integrates the brain. Students having integrated brain are efficient in solving Mathematical problems by using resources of both left and right hemisphere (Oliver, 2009; Arem, 2009). Thus practicing Super Brain Yoga every day helps to alleviate Mathematical Anxiety and also increases scholastic performance of the students in Mathematics exam by enhancing the integration of the brain.

Ganesan $(2008,2012)$ had studied the efficacy of the above Behaviour Modification techniques and found them effective in reduction of neurotic disorders like Anxiety. Whereas, Shunmugom (2014) had studied the efficacy of Adappa Kalam in the management of fear and phobias. These techniques including Super Brain Yoga together were never used before to reduce Anxiety related to Mathematics. Hence there is a need for systematic evaluation of the efficacy of above mentioned techniques in the management of Mathemetics-Anxiety. This study has been undertaken in this direction with a view to implement these effective techniques.

\section{METHODOLOGY}

This research is carried out on 35 students of IX standard, Kendriya Vidalaya. Students were selected for the therapy on the basis of their SUD score. After taking Math autobiography it was revealed that anxiety in Mathematics for the students was developed due to various causes and the students are not Dyslexic. Their Mathematics Anxiety was assessed by using Suri, Monroe and Koc's (2012) short Mathematics Anxiety Rating Scale. Group's hemispheric dominance of the brain was measured by using Taggart and Torrance's Human Information Processing Survey (1984). Group was treated with Behaviour Modification techniques, Adappa Kalam and Super Brain Yoga for four weeks.

Interventions: The following interventions were given for four weeks :- i) Reduction of Rate of Breathing (Ganesan, 2012) ii) Development of Alternate Emotional Responses to Threatening Stimulus (Ganesan, 2008) iii) Laughter Technique (Ganesan, 2008) iv) Adappa Kalam (Shunmugom, 2014) v) Super Brain Yoga (Sui, 2005). They were used to create reciprocal 


\section{Management of Mathematics Anxiety through Behaviour Technology, Super Brain Yoga and Varmalogy in Ninth Standard Students}

inhibition in the Math anxious students and enhanced integration of the brain. Students had relearned the new behaviour to form adaptive habit towards the Mathematics subject.

The pre-intervention score of the group in Mathematics Anxiety is 65. 14, with standard deviation of 4. 89, and post intervention score is 52. 49, with a standard deviation of 6. 99. Mean difference is 12. 66 and critical ration is 8. 97. The pre-intervention SUD score of the group is 60. 63 with a standard deviation of 5 . 54 , and the post intervention score is 48 . 29 , with a standard deviation of 7. 66. Mean difference is 12.34 and Critical Ratio is 10. 20. The preintervention scholastic score of the experimental group is 51. 43, with a standard deviation of 4 . 54 and the post intervention score is 58. 60, with a standard deviation of 5. 11. Mean differences is 7. 17 and Critical Ratio is 8. 90. The result shows that the levels of Mathematics Anxiety, Mathematics SUDs, and scholastic score of the group before and after intervention differ significantly [Table 1].

Table-1: Mathematics Anxiety, Mathematics Suds and Scholsatic Score of the Group Before and After Intervention $(N=35)$

\begin{tabular}{|l|c|c|c|c|}
\hline Factors & $\begin{array}{c}\text { Before } \\
\text { Intervention } \\
\text { Mean } \\
\text { (SD) }\end{array}$ & $\begin{array}{c}\text { After } \\
\text { Intervention } \\
\text { Mean } \\
\text { (SD) }\end{array}$ & $\begin{array}{c}\text { Mean } \\
\text { Difference }\end{array}$ & $\begin{array}{c}\text { Critical } \\
\text { Ratio }\end{array}$ \\
\hline Mathematics & 65.14 & 52.49 & 12.66 & $8.97^{* *}$ \\
Anxiety & $(4.89)$ & $(6.99)$ & & \\
\hline Mathematics & 60.63 & 48.29 & 12.34 & $10.20^{* *}$ \\
Sud Score & $(5.54)$ & $(7.66)$ & & $8.90^{* *}$ \\
\hline Scholastic & 51.43 & 58.60 & 7.17 & \\
Score & $(4.54)$ & $(5.11)$ & & \\
\hline
\end{tabular}

** $\mathrm{P}<0.01$

The group was assessed on Tagarat and Torrance's Human Information Processing Survey (1984). Results showed that before intervention, the dominant mode of information processing of the group was 'Right' with a score of 16, where Left Hemisphere and Integrated were 15, 04 respectively. On reassessing the group after intervention, the dominant mode of processing of the group found to be 'Integrated' with a comparatively higher score of 14, whereas Left Hemisphere and Right Hemisphere score were 12 and 09 respectively [Table 2]. 
Table 2: Human Information Processing Survey of the Group before and After Intervention $(N=35)$.

\begin{tabular}{|c|c|c|c|}
\hline & Left Hemisphere & Right Hemisphere & Integrated \\
\hline $\begin{array}{c}\text { Before } \\
\text { Intervention }\end{array}$ & 15 & 16 & 04 \\
\hline $\begin{array}{c}\text { After } \\
\text { Intervention }\end{array}$ & 12 & 09 & 14 \\
\hline
\end{tabular}

\section{DISCUSSION}

The purpose of the present study was to manage Mathematics Anxiety. For the objective assessment of Mathematics Anxiety, a psychometric scale, namely, short Mathematics Anxiety Rating Scale by Suri, Monroe and Koc (2012) was used and to find the dominant information processing mode of the group, Taggart and Torrance's Human Information Processing Survey was used.

Behaviour Modification techniques, Adappa Kalam and Super Brain Yoga were used to treat the group. The pre-intervention score of the group in Mathematics Anxiety was 65. 14, with standard deviation of 4. 89. The pre-intervention SUD score of the group was 60. 63, with a standard deviation of 5.54 and the pre-intervention scholastic score of the group is 51.43 with a standard deviation of 4. 54. Before intervention, group was assessed on Human Information Processing Survey and the dominant mode of information processing of the group was found to be 'Right'. Group was given intervention for four weeks with Behaviour Modification techniques, like Reduction of Rate of Breathing, Development of Alternate Emotional Responses to Threatening stimulus, Laughter Technique, Adappa Kalam and Super Brain Yoga. Mathematics Anxiety is experienced by a person in different situations and scenarios.

Mathematics Anxiety is experienced while solving a Mathematical problem; while sitting in a Mathematics class room or while solving a problem on the blackboard. Therefore a common stimulus is required which represents Mathematics Anxiety and can trigger anxiety in the math anxious people. After showing this stimulus anxiety is triggered and then interventions are introduced. So, to prepare a stimulus which represents Mathematics Anxiety a sheet of paper is taken and four questions were written based on all four basic operations of Mathematics i.e Division, Multiplication, Addition and Subtraction. To make the problem threatening and complex, five digit questions are used. This sheet of paper is named as Mathematics Anxiety Stimulus and all the interventions are given after presenting this stimulus to the anxious students.

Reduction of rate of breathing activates parasympathetic nervous system and alleviates the effect of sympathetic nervous system, which in turn relaxes the body. So, the rate of reduction of breathing produces response which is incompatible to Mathematics Anxiety. Whereas, through 


\section{Management of Mathematics Anxiety through Behaviour Technology, Super Brain Yoga and Varmalogy in Ninth Standard Students}

Laughter Technique hormone called endorphin is released due to exhaustion of abdominal muscles, which helps to alleviate the pain and stress caused due to Mathematics Anxiety. Finally, by practicing Development of Alternate Response towards Mathematics enables the students to practice six types of emotions after seeing Mathematics as stimulus. The group was first asked to show anger towards the stimulus, and then was asked to laugh at the stimulus followed by singing a song for it, further the group was asked to dance with the stimulus, finally expressed love and worship towards the stimulus. Therefore, by practicing these different emotional responses the conditioned response i.e Mathematics Anxiety, becomes neutral.

Whereas, Adappa Kalam, is a Padu Varmam, which is directly related to brain and correct stimulation of this Varmam point stimulates the parasympathetic nervous system. This in turn alleviates the effect of sympathetic nervous system and thus reduces anxiety. These exercises, through principle of Reciprocal Inhibition, developed alternate emotional responses towards Mathematics Anxiety and found to be incompatible with it.

However, Super Brain Yoga technique enhanced Alpha waves in the brain and Synchronized left and right brain hemispheres (Sui, 2005). Increase in Alpha waves in the brain indicated that the body has become relaxed and thus countered anxiety caused by Mathematics in the group. In addition Super Brain Yoga also synchronized left and right hemispheres of the brain and made the brain integrated. As, students having integrated brain are efficient in solving Mathematical problems by using resources of both left and right hemisphere (Oliver, Erin Michelle, 2009) thus the performance of the group increased significantly.

Group responded well to these interventions and after four weeks, was reassessed on short Mathematics Anxiety Rating Scale. Results showed that the post-intervention score of the group in Mathematics Anxiety was reduced to 52. 49, with a standard deviation of 6.99 and the Critical Ratio was 8. 97. Whereas post-intervention SUD score of the group was reduced to 48 . 29, with a standard deviation of 7.66 and the Critical Ratio was 10. 20. The post intervention scholastic score of the group was increased to 58. 60, with a standard deviation of 5.11 and the Critical Ratio was 8. 90. The results shows that the level of Mathematics Anxiety, Mathematics SUDs, and scholastic score of the group before and after intervention differ significantly [Table-1].

The group was reassessed after intervention on Taggart and Torrance's Information Processing Survey and the results showed that, group's dominant information processing mode was found to be 'integrated'. The increase in number of student from 04 to 14 revealed that the group has become more balanced in its approach and together with logic and intuition has a good scope in Mathematics subject [Table-2].

To conclude, this study has shown that management of Mathematics Anxiety with Behaviour Modification techniques, Varmalogy and Super Brain Yoga are found to be efficient. 


\section{REFERENCES}

Arem, Cynthia (2009). Conquering Math Anxiety: A Self-Help Workbook with CD, Third Edition, California: Brooks/Cole Thomson Learning.

Ashcraft, M.H. (2002). Math anxiety: Personal, educational, and cognitive Consequences. Directions in Psychological Science, 11, 181-185.

Ganesan, V. (2008 , b). Development of Laughter Technique for the Management of Psycho-Physiological Stress Responses. Unpublished Paper. Global Institute of Behaviour Technology, Coimbatore.

Ganesan, V. (2008, a). Development of Alternate Emotional Responses to the Threatening Stimulus. Unpublished Paper. Global Institute of Behaviour Technology, Coimbatore.

Ganesan, V. (2012). Development of a Brief Behaviour Technology for the Reduction of Rate of Breathing. Unpublished Paper. Global Institute of Behaviour Technology, Coimbatore.

Hembree, R. (1990). The nature, effects, and relief of mathematics anxiety. Journal for Research in Mathematics Education, 21, 33-46.Shunmugom, N., Renuka (2012). The foot prints of medical varmalogy: An ancient Indian medical system. Coimbatore: Arts Research Institute.

Oliver, Erin Michelle. (2009). "Relationships between problem solving strategies and brain hemisphericity in high school students. University Honors Program. https://digital.library.txstate.edu/handle/10877/3189.

Reynolds, C. R. and Torrance, E. P. (1978) Perceived changes in styles of learning and thinking (hemisphericity) through direct and indirect training, Journal Creative Behaviour, 12, 247-252.

Shunmugom, N. (2014) Basic Concepts of Medical Vermalogy, Coimbatore, Thirumoolar Varmalogy Institute.

Sui, C. K. (2005), Super Brain Yoga. Manila: The Institute for Inner Studies Publishing Foundation, Inc.

Suri, R., Monroe, K. B. and Koc, U. (2013) Math anxiety and its effects on consumers' preference for price promotion formats, Journal of the Academy of Marketing Science, 41, (3), 271-282.

Taggart, W. F. and Valenzi, E. (1990) Assessing Rational and Intuitive styles: A human information processing metaphor. Journal of Management Studies, 27 (2), 93-116. Varma Kaandam. (M).

Wolpe, J. (1969) The Practice of Behavioral Therapy, New York: Pergamon. 